\title{
Plasma olanzapine concentration: Relation with dose, adherence to medication, and clinical efficacy
}

\author{
Smita Sontakke', Vijay Motghare ${ }^{2, *}$, Ritu Budaniya ${ }^{3}$, Kundan Niwangune $^{4}$, Avinash Turankar ${ }^{5}$ \\ ${ }^{1,5}$ Associate Professor, ${ }^{2}$ Professor and Head, ${ }^{3,4}$ SMO, ${ }^{1,2,5}$ Dept.of Pharmacology, G.M.C Nagpur, Maharashtra, ${ }^{3,4}$ Dept.of \\ Pharmacology, G.S Medical College, Mumbai, Maharashtra, India
}

*Corresponding Author:

Email:vm.motghare@gmail.com

\begin{abstract}
Objective: To estimate plasma olanzapine concentration (POC) using liquid chromatography-mass spectrometry (LCMS) and identify factors that contributes to pharmacokinetic variability of olanzapine.

Materials and Methods: This was a prospective, observational study initiated after approval of institutional ethics committee. Stable patients of schizophrenia on olanzapine, above 18 years of age, of either gender, on olanzapine therapy for at least 12 weeks with no change in dose for at least one week were included. Plasma levels of olanzapine were assessed using HPLC based kit on LCMS. To assess response to treatment patients were subjected to Brief Psychiatric Rating Scale (BPRS) in which lower score indicates better response. Adherence to therapy was assessed by using Morisky 8-Item Medication Adherence Questionnaire in which lower score indicates better adherence. Graph pad prism version 6.0 was used for statistical analysis.

Results: POC was higher in women compared to men. No correlation was observed between POC and age $(\mathrm{r}=0.01343$, $\mathrm{p}=$ $0.9470)$ or daily dose of olanzapine $(\mathrm{r}=-0.2765, \mathrm{P}=0.1626)$. Patients having POC more than $20 \mathrm{ng} / \mathrm{ml}$ had better adherence (Morisky's score 1 or 2) to medication compared to those having POC less than $20 \mathrm{ng} / \mathrm{ml}$. Significant correlation was observed between POC and clinical response $(r=-0.4371, \mathrm{p}=0.0226)$.

Conclusion: TDM of olanzapine is important considering large interpatient variability in POCs at the same dosages. It can also help in improving efficacy, particularly when patients do not respond to therapeutic doses or when they develop adverse effects. Cost of the procedure is a major concern which needs to be considered before this can be established in routine practice.
\end{abstract}

Keywords: TDM, Antipsychotics, BPRS, LCMS, Schizophrenia.

\section{Introduction}

Schizophrenia is a severe mental disorder that is characterized by different psychopathological symptoms like disturbance of the affect, difficulty thinking or dysfunction of perception. Its lifetime prevalence is $0.3-0.7 \% .^{1}$ Olanzapine is considered one of the most effective antipsychotic drugs but is often associated with frequent side effects such as weight gain, dyslipidemia, type II diabetes and heart disease.

Therapeutic drug monitoring (TDM) is being employed for dose individualization, detection of nonadherence, drug interactions. In case of antipsychotics, there is paucity of evidence of concentration effect relationship and side effects. The CATIE trial reported a significantly higher discontinuation rate in patients with low serum concentrations of olanzapine, while patients with high serum concentrations had a significantly higher discontinuation rate due to side effects. ${ }^{2}$ The resulting plasma concentration at a given dose cannot be predicted by the dose. There is an extensive inter individual variability in pharmacokinetics of olanzapine associated with factors such as age, gender, concomitant medications. This is due to inter individual variabilities in drug metabolism by hepatic and extrahepatic enzymes. Other factors, such as drug transporters involved in absorption, distribution and elimination, are probably also relevant. Patients adherence to taking the drug at the prescribed dose and at recommended times is another factor that contributes to the highly variable blood concentrations. ${ }^{3}$
Non Adherence to treatment is an important reason of relapse in schizophrenia patients. ${ }^{4}$ This emphasizes the importance of TDM as a tool to avoid discontinuation of treatment and check for compliance. TDM can help in preventing serious side effects. Most psychiatrists increase doses of antipsychotics to reach clinical effect and stop when side effects occur. However certain silent, but potentially fatal side effects of atypical antipsychotics like serious ventricular arrhythmias and sudden cardiac death have been reported. ${ }^{5}$

The AGNP (Arbeitsgemeinschaftfü $r$ Neuropsychophar makologieund Pharmakopsychiatrie)TDM consensus guidelines strongly recommend monitoring serum concentrations of olanzapine and suggest therapeutic range of $20-80 \mathrm{ng} / \mathrm{ml} .{ }^{2}$ Hence, this study was planned to estimate the plasma concentration of olanzapine using liquid chromatography-mass spectrometry (LC-MS) and identify factors that contribute to the pharmacokinetic variability of olanzapine such as age, gender, concomitant medication, adherence to medication and to know whether there exists a correlation between plasma olanzapine concentration and clinical efficacy.

\section{Materials and Methods}

This was a prospective, observational study initiated after approval of institutional ethics committee. Study was conducted in the Psychiatry OPD 
and department of Pharmacology of a tertiary care teaching hospital.

\section{Inclusion Criteria}

Were stable patients of schizophrenia on olanzapine with or without any concurrent medications, above 18 years of age, of either gender who were on olanzapine therapy for at least 12 weeks with no change in olanzapine dose for at least one week and those willing to give informed consent. Patients with impaired hepatic/renal function (on history/ lab reports) or suffering from any other systemic disorder were excluded.

Patients meeting the selection criteria and/or the legally acceptable representative were briefed about the study. Eligibility of the patients and their capacity to consent were assessed by a psychiatrist. Patient information sheet was provided to 30 patients who met the selection criteria and were willing to participate. To assess response to treatment patients were subjected to the Brief Psychiatric Rating Scale (BPRS) which is a 24-item scale and in which lower score indicates better clinical response. Adherence to therapy was assessed by using Morisky 8-Item Medication Adherence Questionnaire in which lower score indicates better adherence. Patients' OPD cards were analysed to record the following

\section{Information}

Demographic details (age, gender, and weight), diagnosis, names of medicines prescribed with dose, frequency, duration, and adverse drug reactions, if any. HPLC based kit was used for assessing the plasma levels of olanzapine. The kit was used on LCMS (Absciex 3200) instrument having USLC Shimadzu make HPLC. The kits were provided by Recipe entitled 'Neuroleptic' and the software used for analysing was 'Lab Solutions'. About three to five ml blood sample was withdrawn from the patients under all aseptic precautions in plain bottle without anticoagulant. The serum was prepared and processed as per the method described in the kit provided by Recipe. Blood samples for determination of olanzapine plasma concentrations were obtained between 10 and 16 hours after the last dose of olanzapine. The decision to request TDM was made by the patients' psychiatrist on the basis of clinical considerations. Estimation of plasma concentration was done in the LCMS laboratory of department of Pharmacology. BPRS score of $<$ or $=35$ was considered to be an indicator of clinical response. ${ }^{6}$ Spearman correlation test was used to find correlation between plasma concentration and age, gender, daily dose, clinical efficacy and adherence to therapy. Graph pad prism version 6.0 was used for statistical analysis.

\section{Results}

Table 1: Shows the demographic characteristics of study patients

\begin{tabular}{|c|c|}
\hline Demographic Characteristics & \\
\hline $\begin{array}{l}\text { Age in years, mean } \pm \text { SD } \\
\text { Range }\end{array}$ & $\begin{array}{c}46.10 \pm 10.82 \\
25-67 \text { years }\end{array}$ \\
\hline Gender (M:W) & $20: 10$ \\
\hline $\begin{array}{l}\text { Olanzapine daily dose }(\mathrm{mg}), \\
\text { mean } \pm \text { SD } \\
\text { Range }\end{array}$ & $\begin{array}{l}8.083 \pm 4.810 \\
2.5-20 \mathrm{mg}\end{array}$ \\
\hline $\begin{array}{l}\text { Plasma concentration }(\mathrm{ng} / \mathrm{ml}) \text {, } \\
\text { mean } \pm \text { SD } \\
\text { Range }\end{array}$ & $\begin{array}{c}39.96 \pm 56 \\
0-244.4 \mathrm{ng} / \mathrm{ml}\end{array}$ \\
\hline $\begin{array}{l}\text { Plasma concentration(ng/ml), } \\
\text { mean } \pm \text { SD } \\
\text { (After excluding } 3 \text { extreme } \\
\text { values, } n=27) \\
\text { Range }\end{array}$ & $\begin{array}{l}22.87 \pm 13.58 \\
0-49.21 \mathrm{ng} / \mathrm{ml}\end{array}$ \\
\hline $\begin{array}{l}\text { Concomitant medication }(\mathrm{n}=10) \\
\text { Clobazam+ Escitalopram } \\
\text { Clobazam } \\
\text { Escitalopram } \\
\text { Trifluperazine } \\
\text { Clonazepam } \\
\text { Lorazepam } \\
\text { Trihexiphenidyl } \\
\text { Carbamazepine }\end{array}$ & $\begin{array}{c}\text { Number of } \\
\text { patients } \\
1 \\
1 \\
1 \\
2 \\
2 \\
1 \\
1 \\
1\end{array}$ \\
\hline
\end{tabular}

Three patients had plasma olanzapine concentration values that showed extreme deviation from the normal range: $210,126.73$ and 244.43(all in $\mathrm{ng} / \mathrm{mL})$. Hence, these three patients were excluded from other analyses. (Table .2)

Plasma olanzapine concentration was higher in women, $27.79 \pm 13.12($ mean $+\mathrm{SD}) \mathrm{ng} / \mathrm{mL}$ compared to men, $19.98+13.37$ (mean+SD)ng/mL though the difference was not statistically significant. $(\mathrm{P}=0.1527)$ twenty patients received olanzapine monotherapy while ten patients received various co-medications

Table 2: Details of three patients showing huge deviation in plasma concentration.

\begin{tabular}{|c|c|c|c|c|c|c|}
\hline $\begin{array}{c}\text { Age in years } \\
\text { /gender }\end{array}$ & $\begin{array}{c}\text { Plasma } \\
\text { Concentration } \\
\text { (ng/mL) }\end{array}$ & $\begin{array}{c}\text { Dose } \\
(\mathbf{m g})\end{array}$ & $\begin{array}{c}\text { Concomitant } \\
\text { medication }\end{array}$ & $\begin{array}{c}\text { ADR } \\
\text { score }\end{array}$ & $\begin{array}{c}\text { BPRS } \\
\text { score }\end{array}$ \\
\hline 25/M & 210 & 5 & Nil & Nil & 1 & 50 \\
\hline $61 / \mathrm{M}$ & 126.73 & 7.5 & Nil & Weight gain & 1 & 27 \\
\hline $58 / \mathrm{M}$ & 244.43 & 20 & $\begin{array}{c}\text { Trihexiphe- } \\
\text { nydyl 2mg OD }\end{array}$ & $\begin{array}{c}\text { Weight gain, dry mouth, } \\
\text { constipation, akathisia }\end{array}$ & 2 & 54 \\
\hline
\end{tabular}


Fig. 1 shows that there was no correlation between plasma olanzapine concentration and age. $(r=0.01343$, $\mathrm{p}=0.9470)$

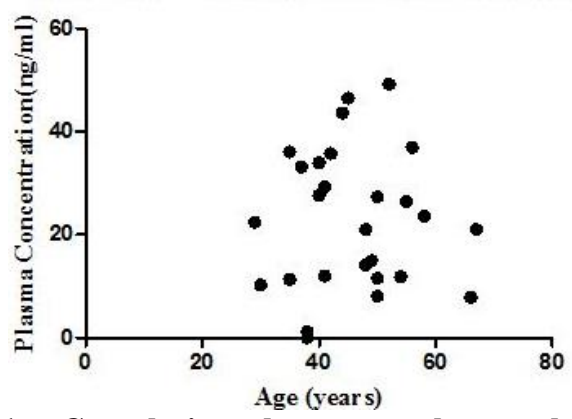

Fig. 1: Correlation between plasm olanzapine concentration and age $(n=27) . r=0.01343, p=0.9470$ (Spearman correlation)

Fig. 2 shows that there was no correlation between daily dose of olanzapine and plasma concentration. $(r=$ $-0.2765, \mathrm{P}=0.1626$ )

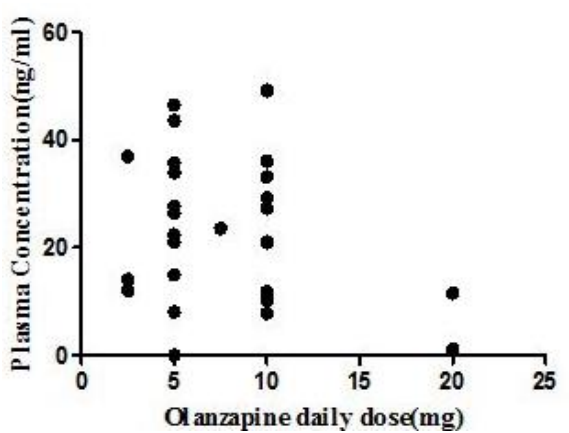

Fig. 2: Correlation between olanzapine daily dose and plasma concentration $(n=27) . r=-0.2765$, $\mathrm{p}=\mathbf{0 . 1 6 2 6}$ (Spearman correlation)

Fig. 3 shows that significantly more patients $(87.5 \%)$ who had plasma olanzapine concentration more than $20 \mathrm{ng} / \mathrm{mL}$ had medium adherence (Morisky's score 1 or 2 ) to medication and fewer patients (12.5\%) had poor adherence (Morisky's score $>2$ ) compared to those having plasma concentration less than $20 \mathrm{ng} / \mathrm{ml}$ though the difference is not statistically significant $(p=0.084$, Fischer's exact test $)$.

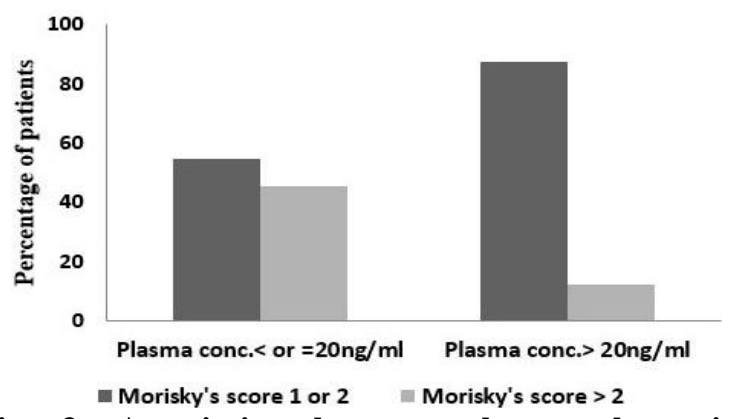

Fig. 3: Association between plasma olanzapine concentration and Morisky's adherence score $(\mathbf{n = 2 7})$
Fig. 4 shows that there was negative correlation between olanzapine plasma concentration and BPRS score $(r=-0.4371, p=0.0226)$, i.e. higher the plasma concentration lower the BPRS score. Lower BPRS score is indicative of clinical response. Hence, negative correlation between olanzapine plasma concentration and BPRS score means, higher the plasma concentration better the clinical response.

Adverse drug reactions reported were as follows (figures in parentheses indicate number of patients): weight gain (15), constipation (11), dry mouth (10), tachycardia (6), drowsiness (2) blurred vision (1), akathisia (1).

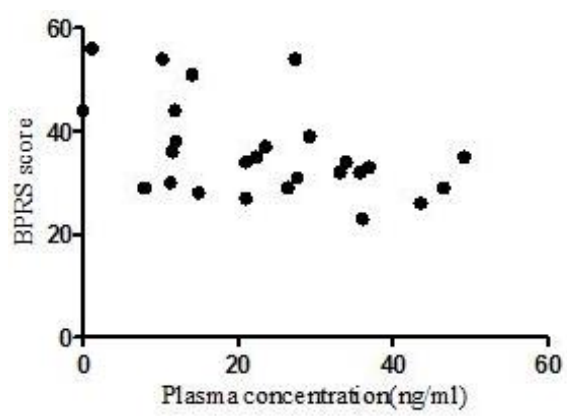

Fig. 4: Correlation between plasma olanzapine concentration and BPRS score $(n=27) . r=0.4371$, $\mathbf{P}=\mathbf{0 . 0 2 2 6}$ (Spearman correlation)

\section{Discussion}

OLZ is one of the most prescribed antipsychotic drugs for the treatment of schizophrenia and bipolar disorder. The results of this study demonstrated significant inter individual variation in plasma OLZ concentrations among patients with schizophrenia. These data are in accordance with several previous studies. ${ }^{7,8}$ This study did not find any correlation between daily dose of olanzapine and plasma concentration. Most of the published studies have reported that plasma level of olanzapine increases linearly with the administered daily oral dose. ${ }^{9-11}$ But it has also been suggested that dose may not always be a good predictor of plasma olanzapine concentration which also depends on pharmacokinetic characteristics of the drug, which varies between individuals owing to factors including differences in age, gender, disease states, smoking habits, and genetic variation in expression of metabolizing enzymes, . ${ }^{11,12}$ Patients who had no change in olanzapine dose for at least one week were included because it has been reported that in clinical practice, the appropriate sampling time for most psychoactive drugs is one week after stable daily dosing. ${ }^{3}$

No correlation was found between plasma olanzapine concentration and age in this study. Whereas some studies found no correlation between olanzapine plasma concentration and age, one study found that age was a major variable for influencing olanzapine plasma levels with higher levels observed in patients 18 years 
or younger while another study reported higher levels in patients 60 years or older. ${ }^{13-16}$ Plasma olanzapine concentration was higher in women compared to men though the difference was not statistically significant. Similar finding is reported in several studies. ${ }^{16-18}$ It is reported that higher concentration in women may probably be because of differences in metabolic capacity of the CYP450 isoenzyme system due to which olanzapine clearance is lower in women than in men. ${ }^{3,6,19,20}$ It has also been suggested that gender differences in olanzapine pharmacokinetics may reflect differences in drug-metabolizing phenotypes between males and females, a hypothesis which is actualized by the apparent inhibition of CYP1A2 metabolism/activity by estrogens. ${ }^{21}$ Moreover, gender differences in body composition may lead to higher volumes of distribution of lipophilic drugs in females than in males, which theoretically could result in higher steady-state trough levels of most psychotropic agents in female patients. ${ }^{22}$

Among various factors which may affect plasma concentration, adherence to medication is an important one. Among patients who had plasma concentration above 20ng/mL, majority had better adherence (Morisky score 1 or 2) to medication compared to those having plasma concentration below 20ng/ml. Hence, adherence to medication is an important factor which determines plasma concentration which in turn shows correlation with clinical efficacy. Estimating adherence to medication particularly in patients showing poor response to treatment would help in identifying the cause of inadequate response, whether due to poor adherence or not. Subsequently adequate measures can be taken to improve adherence to medication in these patients. If adherence is found to be adequate search for other causes of poor response to treatment can be done. If patients are known to be non-adherent to the medication frequency of TDM may be increased. ${ }^{3}$ Thus, TDM may also be useful in monitoring adherence to medication. Patient's adherence to medication is also one of the factor that may be responsible for the highly variable plasma olanzapine concentrations observed in this study.

Significant negative correlation was observed between BPRS score, which is indicative of clinical response (lower the score better the response) and plasma concentration. Studies strongly indicate a relationship between clinical outcomes and plasma olanzapine concentration. ${ }^{3}$ A study in patients of acute schizophrenia reported significant curvilinear correlation between plasma olanzapine concentration and clinical improvement. ${ }^{23}$ In another study, $52 \%$ of schizophrenia patients with olanzapine concentrations > or=23.2 ng/mL responded, whereas only $25 \%$ of patients with concentrations $<23.2 \mathrm{ng} / \mathrm{mL}$ responded, hence, the authors suggested an olanzapine concentration $>$ or $=23.2 \mathrm{ng} / \mathrm{mL}$ to be a predictor of therapeutic response. 6
Despite agreement on the minimum effective therapeutic concentration $(20 \mathrm{ng} / \mathrm{mL})$, several levels have been proposed for the maximum safe therapeutic level of olanzapine (upper limit of the target range), ranging from $40 \mathrm{ng} / \mathrm{mL}$ to $80 \mathrm{ng} / \mathrm{mL} \cdot{ }^{24,25}$ It has also been suggested that plasma levels of more than 40 $\mathrm{ng} / \mathrm{ml}$ are unlikely to show any benefit over lower plasma concentrations. ${ }^{11}$ Even in this study maximum clinical benefit was obtained in patients having plasma concentration between 20 to $40 \mathrm{ng} / \mathrm{mL}$. Three patients showed plasma concentration values which deviated widely from the therapeutic range: 210,126.73 and 244.43(all units in $\mathrm{ng} / \mathrm{mL}$ ). Detail analysis of these three patients did not reveal any obvious cause for such huge deviation in plasma concentration as can be seen from (Table 2).

The importance of using plasma concentrations of antipsychotics to monitor patients with schizophrenia is a debatable issue but there is growing evidence that it can improve efficacy, especially when patients do not respond to therapeutic doses or when they develop adverse effects. ${ }^{12}$ This is particularly important considering large interpatient variability in plasma olanzapine concentrations at the same dosages as is seen in this study and in other studies as well. ${ }^{2}$ TDM of antipsychotics is also important since there is no objective criteria to assess response to treatment in patients of schizophrenia.

To conclude, though TDM of antipsychotic drugs is a powerful tool that allows tailoring the treatment to the specific needs of individual patients, cost of the procedure is a major concern which needs to be considered before this can be established in routine practice.

\section{References}

1. McGrath J, Saha S, Chant D, Welham J. Schizophrenia: a concise overview of incidence, prevalence, and mortality. Epidemiol Rev.2008;30:67-76.

2. Lieberman JA, Stroup TS, McEvoy JP, Swartz MS, Rosenheck RA, Perkins DOet al. Effectiveness of antipsychotic drugs in patients with chronic schizophrenia. N Engl J Med. 2005;353:1209-23.

3. Grundmann M, Kacirova1 I, Urinovska R. Therapeutic Drug Monitoring Of Atypical Antipsychotic Drugs (Review). Acta Pharm. 2014;64:387-401.

4. Leucht S, Barnes TR, Kissling W, Engel RR, Correll C, Kane JM. Relapse prevention in schizophrenia with newgeneration antipsychotics: a systematic review and exploratory meta-analysis of randomized, controlled trials. Am J Psychiatry. 2003;160:1209-22.

5. Ray WA, Meredith S, Thapa PB, Meador KG, Hall K, Murray KT. Antipsychotics and the risk of sudden cardiac death. Arch Gen Psychiatry. 2001;58:1161-7.

6. Perry PJ, Lund BC, Sanger T, Beasley C. Olanzapine plasma concentrations and clinical response: acute phase results of the North American Olanzapine Trial. J ClinPsychopharmacol. 2001;21(1):14-20.

7. Callaghan JT, Bergstrom RF, Ptak LR, Beasley CM. Olanzapine. Pharmacokinetic and pharmacodynamic profile. ClinPharmacokinet. 1999; 37:177-93. 
8. Skogh E, Reis M, Dahl ML, Lundmark J, Bengtsson F. Therapeutic drug monitoring data on olanzapine and its $\mathrm{N}$-demethyl metabolite in the naturalistic clinical setting. Ther Drug Monit. 2002;24:518-26.

9. Aravagiri M, Ames D, Wirshing WC, Marder SR. Plasma level monitoring of olanzapine in patients with schizophrenia: determination by high-performance liquid chromatography with electrochemical detection. Ther Drug Monit. 1997;19(3):30713.

10. Theisen FM, Haberhausen M, Schulz E, Fleischhaker C, Clement HW, Heinzel-Gutenbrunner Met al. Serum levels of olanzapine and its $\mathrm{N}$-desmethyl and 2hydroxymethyl metabolites in child and adolescent psychiatric disorders: effects of dose, diagnosis, age, sex, smoking, and comedication. Ther Drug Monit. 2006;28(6):750-9.

11. Bishara D, Olofinjana O, Sparshatt A, Kapur S, Taylor D, Patel M. Olanzapine: A Systematic Review and MetaRegression of the Relationships Between Dose, Plasma Concentration, Receptor Occupancy, and Response. Journal of Clinical Psychopharmacology 2013; 33(3):329-35.

12. Mauri MC, Volonteri LS, Colasanti A, Fiorentini A, de Gaspari IF, Bareggi SR, Clinical pharmacokinetics of atypical antipsychotics. A critical review of the relationship between plasma concentrations and clinical response. Clin. Phamacokinet 2007;46:359-88.

13. Bergemann N, Frick A, Parzer P, Kopitz J. Olanzapine plasma concentration, average daily dose, and interaction with co-medication in schizophrenic patients. Pharmacopsychiatry. 2004;37:63-8.

14. Linnet K, Olesen OV. Free and glucuronidated olanzapine serum concentrations in psychiatric patients: influence of carbamazepine comedication. Ther Drug Monit. 2002;24:512-7.

15. Aichhorn W, Marksteiner J, Walch T, Gerald Zernig, Hartmann Hinterhuber, ChristophStuppaeck et al. Age and gender effects on olanzapine and risperidoneplasma concentrations in children and adolescents. $J$ Child AdolescPsychopharmacol. 2007;17:665-74.

16. Gex-Fabry M, Balant-Gorgia AE, Balant LP. Therapeutic drug monitoring of olanzapine: the combined effect of age, gender, smoking, and comedication. Ther Drug Monit 2003;25:46-53.
17. Weiss U, Marksteiner J, Kemmler G, Saria A, Aichhorn $\mathrm{W}$. Effects of age and sex on olanzapine plasma concentrations. J ClinPsychopharmacol. 2005;25: 570-4.

18. Citrome L, Stauffer VL, Chen L, Kinon BJ, Kurtz DL, Jacobson JGet al.Olanzapine plasma concentrations after treatment with 10,20 , and $40 \mathrm{mg} / \mathrm{d}$ in patients with schizophrenia: an analysis of correlations with efficacy, weight gain, and prolactin concentration. $J$ ClinPsychopharmacol. 2009;29(3):278-83.

19. Kelly DL, Conley RR, Tamminga CA. Differential olanzapine plasma concentrations by sex in a fixed-dose study. Schizophr Res 1999;40:101- 4.

20. Bigos KL, Pollock BG, Coley KC, Miller DD, Marder SR, Aravagiri M et al. Sex, race, and smoking impact olanzapine exposure. J ClinPharmacol. 2008;48:157-65.

21. Pollock BG, Wylie M, Stack JA,Sorisio DA, Thompson DS, Kirshner MA et al. Inhibition of caffeine metabolism by estrogen replacement therapy in postmenopausal women. J ClinPharmacol. 1999;39:936-40.

22. Tore Haslemo. Pharmacokinetic Variability of Olanzapine- A Study Based on Therapeutic Drug Monitoring Data. Dissertation for the Degree Philosophiae Doctor (Ph.D.) Oslo 2012. Department of Pharmaceutical Biosciences School of Pharmacy Faculty of Mathematics and Natural Sciences University of Oslo. Center for Psychopharmacology, Diakonhjemmet Hospital Oslo.pg. 27.

23. Mauri MC, Steinhilber CP, Marino R, Invernizzi E, Fiorentini A, Cerveri Get al. Clinical outcome and olanzapine plasma levels in acute schizophrenia. Eur Psychiatry. 2005;20(1):55-60.

24. Rao ML, Hiemke C, Grasmader K, Baumann P. Olanzapine: pharmacology, pharmacokinetics and therapeutic drug monitoring. FortschrNeurolPsychiatr 2001;(69):510-7.

25. Hiemke C, Dragicevic A, Grunder G,Hättter S, Sachse J, Vernaleken I et al. Therapeutic monitoring of new antipsychotic drugs. Ther Drug Monit 2004;(26):156-60. 